\title{
Effect on prostate volume following neoadjuvant treatment with an androgen receptor inhibitor monotherapy versus castration plus an androgen receptor inhibitor in prostate cancer patients intended for curative radiation therapy: A randomised study
}

\author{
KHAIRUL MAJUMDER ${ }^{1,2}$, YVONNE BRANDBERG ${ }^{1}$, HEMMING JOHANSSON $^{2}$, \\ ENRIQUE CASTELLANOS ${ }^{2}$, ANDERS ULLÉN ${ }^{1,2}$, BO LENNERNÄS ${ }^{3}$ and STEN NILSSON ${ }^{1}$ \\ ${ }^{1}$ Department of Oncology-Pathology, Karolinska Institutet, 17176 Stockholm; ${ }^{2}$ Department of Oncology, \\ Karolinska University Hospital, 17176 Stockholm; ${ }^{3}$ Department of Oncology, \\ Örebro University Hospital, 70185 Örebro, Sweden
}

Received June 20, 2017; Accepted October 30, 2017

DOI: $10.3892 / \mathrm{mco} .2017 .1487$

\begin{abstract}
To avoid pubic arch interference, prostate cancer patients are treated with neoadjuvant androgen deprivation therapy (ADT) to achieve prostate volume (PV) reduction prior to radiation treatment. The aim of the present randomised study was to compare the effects on PV of two regimens of ADT, an androgen receptor inhibitor monotherapy vs. castration plus an androgen receptor inhibitor. Consecutive patients with non-metastatic prostate cancer were included in a randomised neoadjuvant study, comparing an androgen receptor inhibitor monotherapy vs. castration plus an androgen receptor inhibitor. PV was assessed prior to the start of endocrine neoadjuvant treatment and prior to the start of radiation therapy (RT). PV assessment was performed by transrectal ultrasound. A total of 110 patients were included. Final sample constituted $88(80 \%)$ patients due to lack of PV information. Castration plus an androgen receptor inhibitor was more effective in $\mathrm{PV}$ reduction compared with an androgen receptor inhibitor alone $(\mathrm{P}<0.001)$. Planning target volume decreased in the combination arm. There was no significant difference in clinical or demographic or length of neoadjuvant hormonal treatment between the groups. Overall, a significantly larger PV reduction was achieved by castration plus androgen receptor inhibitor, as compared with androgen receptor inhibitor monotherapy. The PV reduction, however, appeared not to translate into better health associated quality of life during the subsequently given curative intended combined EBRT and HDR-brachytherapy. Potential differences
\end{abstract}

Correspondence to: Dr Khairul Majumder, Department of Oncology, Karolinska University Hospital, 17176 Stockholm, Sweden

E-mail: khairul.majumder@karolinska.se

Key words: prostate cancer, neo-adjuvant, hormonal therapy, radiotherapy, prostate volume between these two treatments regarding anti-tumor effects on micro metastatic disease and radiation potentiating effect remains to be addressed in future prospective trials.

\section{Introduction}

Prostate volume (PV) plays an important role in planning for radiation therapy (RT). Smaller PV implies smaller areas of organs-at-risk in Planning Target Volume (PTV) before start of RT, thus minimizing side effects from normal surrounding tissues. Larger PV, on the other hand, demands radiation of larger areas, thus increasing the risk of side effects. One theoretical rationale for offering endocrine therapy in the neoadjuvant setting before RT is to reduce the PV. There is convincing evidence from several previous studies that a short period of ADT prior to the radiation therapy may reduce PV by $25-40 \%$ (1-6). ADT used in these studies varied among luteinizing hormone release hormone (LHRH)-analogue alone, or in combination with anti-androgen or surgical castration only, or a combination of anti-androgen and 5-alfa reductase inhibitor. Whittington et al (7) showed, by using LHRH-analogue, that the greatest decrease of PV occurred in those with the largest PV at baseline. Thus, it remains as physicians' options to use $\mathrm{ADT}$ to get maximum volume reduction.

There are different methods for volume measurement of prostate gland. Minimally invasive surgery has shown that ultrasound is the ideal imaging system for targeting treatments because of its ease of use and the absence of adverse effects (8). Computed tomography (CT) derived estimations of PVs are generally larger than PV assessed by Magnetic Resonance, especially towards the seminal vesicles and the apex of the prostate (9). In addition, a PV evaluation in ten patients before prostate brachytherapy showed that the CT-based prostate volumes ranged from 31.1 cubic centimetres (cc) to $48.1 \mathrm{cc}$, whereas corresponding figures for transrectally ultrasound (TRUS)-based volumes were 26.6 to $46.4 \mathrm{cc}$ (10). Furuya et al (11) showed prospectively, by using TRUS, that ADT significantly decreased prostate- and seminal vesicles 
volumes. Thus, TRUS assessed PV is expected to generate PTV's including minimum volumes of organs-at-risk.

There is, to our knowledge, no published randomised study addressing differences in PV reduction following treatment with an androgen receptor inhibitor monotherapy vs castration plus an androgen receptor inhibitor. Thus, the aim of the present study was to compare changes in PV in the randomised ADT study (12). The hypothesis was that PV reduction would be larger in the combined group compared to androgen receptor inhibitor monotherapy, and that PTV subsequently would be smaller in the castration plus androgen receptor inhibitor group.

\section{Patients and methods}

Patients. Consecutive patients with localised prostate cancer intended for curative treatment with radiotherapy were included in the randomised ADT study (12). The primary aim of the ADT study was to compare health-related quality-of-life (HRQoL) between the two groups over time. All patients were treated at a single institution, the Department of Oncology, Karolinska University Hospital, Sweden. Included patients signed an informed consent form before randomisation to an androgen receptor inhibitor monotherapy or to castration plus an androgen receptor inhibitor.

Methods. Between 2005 and 2011 a total of 110 patients were included in the ADT study (12). Before 2008, the referring urologist measured PV (Volume 1) before referral to the Department of Oncology. Between 2008 and 2011 PV measurement were routinely performed at the Department of Oncology to ensure homogeneity. Second PV measurement (Volume 2) was performed before start of HDR brachytherapy, about three months after randomization. Planning target volume was decided upon by computerized tomography.

Randomization. Eligible patients were randomly allocated between the treatment arms in a 1:1 ratio (Fig. 1). A total of 55 patients were randomised to Group A (Bicalutamide $150 \mathrm{mg}$ orally daily) vs. 55 patients who were randomised to Group B (Bicalutamide $50 \mathrm{mg}$ orally daily + Implant Goserelin 3,6 mg sub-cutaneous every $28 \pm 2$ days). Patients in both groups were offered the option to use anti-oestrogen orally if needed against breast-tenderness or gynecomastia. The Clinical Trials Unit, located at the Karolinska University Hospital, performed the randomization per pre-constructed randomization lists. By use of permuted block technique, randomization lists were generated per standard procedures. Stratification was done for age ( $\leq 65,>65$ years) and lymph node dissection (yes or no).

PV assessment. TRUS (BK Medical endocavity biplane Transducer 8848.12-4 MHz) was used to measure PV at the Department of Oncology. The procedure was performed in an operating room with the patient in the dorsal lithotomy position. The TRUS transducer was positioned in a stepping device that allowed the prostate to be scanned systematically in both axial and sagittal planes. The ultrasound system permitted very accurate volume and surface outline calculations of the prostate and seminal vesicles. The height and width were measured in the transverse plane and length in the sagittal

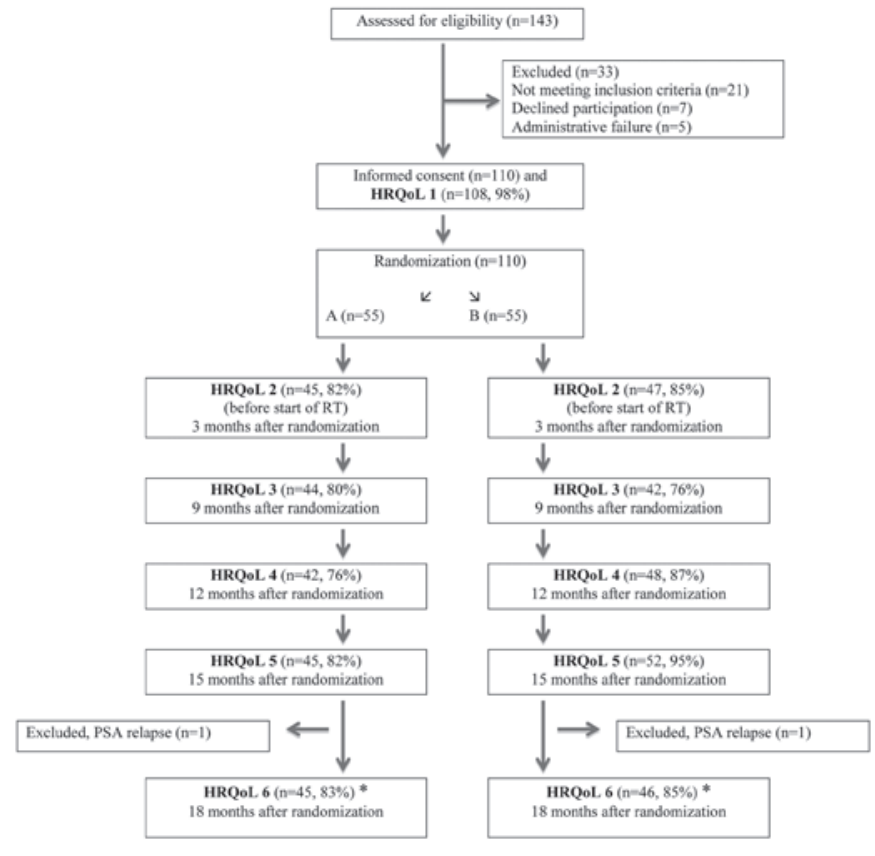

Figure 1. Consort diagram representing screening and randomisation between the two groups $(n=110)$. The nominator was 54 in both arms at the last assessment.

plane. Ultrasound apparatus then generated the volume automatically. The results were recorded in the patients' medical chart, providing the physicians access to individual results during patient consultations.

Assessment of HRQoL. The patients completed HRQoL questionnaires after informed consent and before randomisation, and again before start of RT, about three months after randomisation. The European Organization for Research and Treatment of Cancer Quality of Life Core Questionnaire (EORTC QLQ-C30) and the EORTC Prostate Cancer Specific Module (EORTC PR-25) were used $(13,14)$.

Statistical methods. Absolute differences in PV between the baseline and the follow-up assessment were tested for each group by the paired t-test. The mean paired change is presented together with $95 \%$ confidence intervals. Differences between the study groups at baseline and at follow-up were estimated and tested using linear regression models. At the follow-up visit differences were estimated both by not including Volume 1 in the model (univariate analysis), and by including the Volume 1 in the model (multivariate analysis). P-values from these models refer to Wald tests. All statistical analyses were based on the 'intention-to-treat' principle.

The cut-off $20 \%$ for decrease in PV was set as minimum decrease, based on the observation from similar studies (1-5). The cut-off was set to $10 \%$ for increase, based on one study done by Henderson and co-workers (5) where $8 \%$ increase in PV was noted in patients without hormonal therapy. The between group comparison of PTV was performed by unpaired t-test.

The HRQoL results are presented as mean differences and $95 \%$ confidence intervals (CIs). The reported P-values are two-sided and refer to Wald tests. A P-value of $\leq 0.05$ was considered statistically significant. 
Table I. Patient characteristics according to randomization arms.

\begin{tabular}{|c|c|c|c|}
\hline & $\operatorname{Arm~A~n=45~}$ & Arm B n=43 & Total $n=88$ \\
\hline Age (year) mean (range) & $67(54-76)$ & $66(53-78)$ & \\
\hline \multicolumn{4}{|l|}{ T-stage, n $(\%)$} \\
\hline $\mathrm{T} 1 \mathrm{C}$ & $12(27)$ & $14(33)$ & 26 \\
\hline $\mathrm{T} 2$ & $26(58)$ & $22(51)$ & 48 \\
\hline $\mathrm{T} 2-3$ & $3(7)$ & $2(5)$ & 5 \\
\hline $\mathrm{T} 3$ & $4(9)$ & $5(12)$ & 9 \\
\hline \multicolumn{4}{|l|}{ Gleason score, n (\%) } \\
\hline 6 & $12(27)$ & $8(19)$ & 20 \\
\hline 7 & $31(69)$ & $34(79)$ & 65 \\
\hline 8 & $0(0)$ & $1(2)$ & 1 \\
\hline 9 & $2(4)$ & $0(0)$ & 2 \\
\hline \multicolumn{4}{|l|}{ PSA at inclusion } \\
\hline Mean (range) & $10.0(2.7-38.0)$ & $8.8(2.9-24.0)$ & \\
\hline \multicolumn{4}{|l|}{ Order of RT, n (\%) } \\
\hline BTx2-Ext & $33(73)$ & $33(77)$ & 66 \\
\hline Ext-BTx2-Ext & $5(11)$ & $3(7)$ & 8 \\
\hline Ext-BTx2 & $5(11)$ & $7(16)$ & 12 \\
\hline BT-Ext-BT & $2(4)$ & $0(0)$ & 2 \\
\hline \multicolumn{4}{|l|}{ Volume 1 before } \\
\hline \multicolumn{4}{|l|}{ Randomization (cc) } \\
\hline Mean (range) & $33(11-50)$ & $30(18-50)$ & 31.5 \\
\hline \multicolumn{4}{|l|}{ Volume 2 before RT (cc) } \\
\hline Mean (range) & $27,2(15-42)$ & $21,6(11,8-30,4)$ & \\
\hline \multicolumn{4}{|c|}{$\begin{array}{l}\text { Time between volume } 1 \text { and volume } 2 \\
\text { (number of weeks) }\end{array}$} \\
\hline Mean (range) & $13(9-22.5)$ & $13.5(8-23)$ & \\
\hline
\end{tabular}

The present study was approved by the Ethics Committee at the Karolinska Institutet, Stockholm, Sweden (Dnr. 2008/1222-32).

\section{Results}

The baseline clinical characteristics by randomisation groups are presented in Table I. A total of 110 patients were included in the neoadjuvant study (12). Eleven patients were, however, not included in the present analyses as information of PV at baseline was lacking. Another 11 patients were excluded because they were treated with EBRT only, where volume measurement was not performed routinely at RT start. Reasons for not being subjected for combined EBRT-brachytherapy (11 patients) were the following: 'No decrease in PV after AA' (1 patient), 'PV>65 cc' (3 patients), 'Earlier transurethral resection of prostate' (3 patients), 'Co-morbidity' (3 patients), 'Lobus tertius' (1 patient). Thus, 88 patients $(80 \%)$ remained to be analysed, 45 patients (51\%) in Group A and 43 patients (49\%) in Group B. Two patients switched over from Group A to the Group B (however treated with LHRH analogue only) due to liver toxicity, but were included per the intention-to-treat principle.

Castration plus an androgen receptor inhibitor was more effective in $\mathrm{PV}$ reduction as compared to androgen receptor inhibitor monotherapy $(\mathrm{P}<0.001)$ (Table II). Mean volume reduction was $28 \%$ (30 to $21.6 \mathrm{cc}$ ) and $17.5 \%$ (33 to $27.2 \mathrm{cc}$ ) respectively. In Group A, PV was reduced by $\geq 20 \%$ in 23 patients (51\%). Corresponding fig. for Group B was 34 patients (79\%). PV was increased by $\geq 10 \%$ in 4 patients $(8 \%)$ in Group A and in 1 patient $(2 \%)$ in Group B. The time between the assessments was similar in both groups. There was no statistically significant difference in duration of neoadjuvant treatment or in clinical and demographic variables between the two groups.

A comparison of prostate target volume (PTV) for the planning of radiotherapy revealed a statistically significant difference $(\mathrm{P}>0.001)$ between the two groups in mean volume, $47.4 \mathrm{cc}(\mathrm{SD}=12.8)$ in Group A vs. $37.9 \mathrm{cc}(\mathrm{SD}=7.6)$ in Group B.

At the assessment after the first 3 months statistically significant differences between the groups in 'overall quality of life', 'fatigue', and 'sexual interest', favouring Group A (Table III). No other between group differences was found for HRQoL.

\section{Discussion}

PV plays an important role when planning irradiation with curative intention in prostate cancer, since large PTV may affect organs at risk and subsequent radiation related 
side effects. PV reduction is one of the rationales for using neo-adjuvant ADT to minimize the radiation field, and thus the side effects. In the present, prospective study, castration plus an androgen receptor inhibitor significantly decreased PV more than androgen receptor inhibitor monotherapy and subsequently PTV was smaller in Group B than in Group A. One retrospective study showed, in 22 patients, that the median percentage of volume reduction after combination group was $25 \%$ (4). Another non-randomised prospective study showed an $8 \%$ volume reduction in the bicalutamide group compared to a $26 \%$ reduction in the goserelin group after final analysis of 81 patients (5). Thus, our hypothesis was in concordance with results from other studies.

In the present study PV was increased by $\geq 10 \%$ in 4 patients (8\%) in Group A and in 1 patient (2\%) in Group B. This finding is surprising, as no other study has, to our knowledge, reported similar findings. The increase in PV during ADT treatment might be explained by the fact that the same physician did not assess PV at the first point of assessment and at the second measurement three months later. Thus, the absolute figures for PV should be considered with caution. Ideally, the same physician should have performed both assessments. Kucway et al (15) mentioned in their study that one of the sources of error in measurement of PV was inter-physician variability, and pointed out that variability in PV measurement is unavoidable. Patients in both randomised groups in our study suffered this variability to the same extent. Thus, we do not consider this to hamper our results.

RT has many side effects that are expected to negatively influence patients' quality of life. A cross sectional study of 989 prostate cancer patients treated with RT showed that defecation urgency was the most common symptom among survivors after 2-14 years' follow-up, followed by faecal leakage and loose stools (16). Similar results have been presented in patients treated with pelvic irradiation, both men and women, where defecation urgency and faecal leakage has been identified as the most disturbing of all radiation-induced symptoms (17-21). In the neoadjuvant study (12), differences between the groups at the three months' assessment, before the start of RT, were found for 'overall quality of life', 'fatigue' and 'sexual interest', all in favour of monotherapy. These differences were expected, as castration obtained in Group B might cause these problems. About 18 months after randomization (around nine months after termination of RT), statistically significant differences were found for 'cognitive functioning' and 'sexual interest' (12). There were, however, no differences in urinary or bowel symptoms at this assessment point. These findings were surprising, as the smaller volumes irradiated in the combination group were expected to result in lower levels of urinary and bowel symptoms. One possible explanation may be that combined EBRT BT irradiated both groups, and that the small putative differences in side-effects caused by volume differences of the external RT were outweighed by side effects from the brachytherapy.

The randomized prospective single-centre design is the strength of our study. In addition, TRUS was used to perform assessment of PV, which is one of the most reliable methods for this kind of assessment. Two urologic-oncologists, knowledgeable of radiation planning in prostate cancer, screened all patients' medical charts carefully. One weakness of the study is that the results would be more reliable if PV measurement 
Table III.EORTC QLQ-30 and QLQ-PR25 mean values and SD at the three months' assessment and mean scales differences (CI) corrected for baseline between Group A and Group B.

\begin{tabular}{|c|c|c|c|c|}
\hline Variable & Group A mean (SD) & Group B mean (SD) & Difference $(\mathrm{CI})$ & P-value \\
\hline \multicolumn{5}{|l|}{ EORTC QLQ-C30 } \\
\hline Overall quality of life $\mathrm{a}^{\mathrm{a}}$ & $80(22)$ & $74(19)$ & $-9(-15$ to -3$)$ & 0.006 \\
\hline Physical functioning ${ }^{\mathrm{a}}$ & $92(11)$ & $92(12)$ & $-1(-4$ to 3$)$ & NS \\
\hline Role functioning ${ }^{\mathrm{a}}$ & $94(14)$ & $90(18)$ & $-5(-12$ to 2$)$ & NS \\
\hline Emotional functioning ${ }^{\mathrm{a}}$ & $84(23)$ & $84(18)$ & $-3(-9$ to 4$)$ & NS \\
\hline Cognitive functioning ${ }^{\mathrm{a}}$ & $91(15)$ & $87(17)$ & $-5(-11$ to 1$)$ & NS \\
\hline Social functioning ${ }^{\mathrm{a}}$ & $89(19)$ & $89(18)$ & $-2(-9$ to 5$)$ & NS \\
\hline Fatigue $^{\mathrm{b}}$ & $18(20)$ & $23(18)$ & $8(1$ to 15$)$ & 0.023 \\
\hline Nausea and vomiting & $4(9)$ & $3(7)$ & $-1(-5$ to 2$)$ & NS \\
\hline Pain & $10(18)$ & $7(16)$ & $-5(-11$ to 1$)$ & NS \\
\hline Dyspnoea & $15(23)$ & $18(24)$ & $3(-5$ to 12$)$ & NS \\
\hline Insomnia & $21(27)$ & $27(29)$ & $8(-3$ to 18$)$ & NS \\
\hline Appetite loss & $2(8)$ & $3(9)$ & $0(-3$ to 2$)$ & NS \\
\hline Constipation & $6(15)$ & $6(19)$ & $2(-5$ to 9$)$ & NS \\
\hline Diarrhoea & $7(15)$ & $5(12)$ & $-2(-8$ to 4$)$ & NS \\
\hline \multicolumn{5}{|l|}{ EORTC PR-25 } \\
\hline Sexual interest $\mathrm{t}^{\mathrm{a}}$ & $31(29)$ & $10(14)$ & $-21(-30$ to -13$)$ & $<0.001$ \\
\hline Sexual functioning ${ }^{\mathrm{a}}$ & $67(19)$ & $59(12)$ & $-15(-30$ to 1$)$ & NS \\
\hline Urinary problems ${ }^{\mathrm{b}}$ & $14(12)$ & $16(17)$ & $3(-3$ to 10$)$ & NS \\
\hline Bowel problems ${ }^{\mathrm{b}}$ & $3(7)$ & $5(7)$ & $3(-1$ to 6$)$ & NS \\
\hline Use of pads ${ }^{b}$ & $16(11)$ & $16(10)$ & $0(-4$ to 4$)$ & NS \\
\hline
\end{tabular}

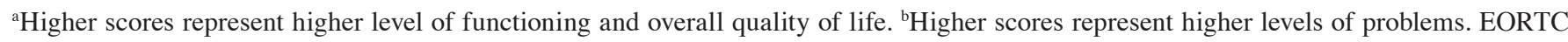
QLQ-C30, European Organization for Research and Treatment of Cancer Quality of Life Core Questionnaire; SD, standard deviation; CI, confidence interval.

had been confined to the same physician at both points of assessment. Sample size is another weakness of the study.

In summary, a significantly less prominent PV reduction was achieved following neoadjuvant ADT using an androgen receptor inhibitor monotherapy compared to castration plus an androgen receptor inhibitor. This PTV reduction, however, appeared not to translate into a more favourable quality of life profile during the subsequently given curative combined EBRT-brachytherapy. Potential differences regarding anti-tumoral effects on micro metastatic disease and radiation potentiating remains to be addressed in future prospective trials.

\section{References}

1. Lee WR: The role of androgen deprivation therapy combined with prostate brachytherapy. Urology 60 (3 Suppl 1): S39-S44, 2002.

2. Merrick GS, Butler WM, Wallner KE, Galbreath RW, Allen ZA and Kurko B: Efficacy of neoadjuvant bicalutamide and dutasteride as a cytoreductive regimen before prostate brachytherapy. Urology 68: 116-120, 2006.

3. Nishiyama T, Tomita Y and Takahashi K: Influence of androgen deprivation therapy on volume of anatomic zones of prostate in patients with prostate cancer using magnetic resonance imaging. Urology 63: 917-921, 2004.

4. Zelefsky MJ, Leibel SA, Burman CM Kutcher GJ, Harrison A, Happersett L and Fuks Z: Neoadjuvant hormonal therapy improves the therapeutic ratio in patients with bulky prostate cancer treated with three-dimensional conformal radiation therapy. Int J Radiat Oncol Biol Phys 29: 755-761, 1994.
5. Henderson A, Langley SM and Laing RW: Is bicalutamide equivalent to goserelin for prostate volume reduction before radiation therapy? A prospective, observational study. Clin Oncol (R Coll Radiol) 15: 318-321, 2003.

6. Shearer RJ, Davies JH, Gelister JS and Dearnaley DP: Hormonal cytoreduction and radiotherapy for carcinoma of the prostate. $\mathrm{Br}$ J Urol 69: 521-524, 1992.

7. Whittington R, Broderick GA, Arger P, Malkowicz SB Epperson RD, Arjomandy B and Kassaee A: The effect of androgen deprivation on the early changes in prostate volume following transperineal ultrasound guided interstitial therapy for localized carcinoma of the prostate. Int J Radiat Oncol Biol Phys 44: 1107-1110, 1999.

8. Carter SS, Torp-Pedersen ST and Holm HH: Ultrasound-guided implantation techniques in treatment of prostate cancer. Urol Clin North Am 16: 751-762, 1989.

9. Rasch C, Barillot I, Remeijer P, Touw A, van Herk M and Lebesque JV: Definition of the prostate in CT and MRI: A multi-observer study. Int J Radiat Oncol Biol Phys 43: 57-66, 1999.

10. Badiozamani KR, Wallner K, Cavanagh W and Blasko J: Camparability of CT-based and TRUS-based prostate volumes. Int J Radiat Oncol Biol Phys 43: 375-378, 1999.

11. Furuya R, Hisasue S, Furuya S, Saitoh N, Ogura H, Takahashi S and Tsukamoto T: Fate of seminal vesicles and prostate after medical castration: How long is the optimal duration of neoadjuvant treatment for prostate cancer before radiation? Urology 72 : 417-421, 2008.

12. Majumder K, Nilsson S, Johansson H, Ullén A, Lennernäs B, Bergenmar $M$ and Brandberg Y: Higher sexual interest with androgen receptor inhibitor monotherapy than with castration plus an androgen receptor inhibitor in prostate cancer patients treated with curative radiotherapy, but otherwise small health-related quality of life differences: A randomised prospective 18-month follow-up study. Eur J Cancer 65: 43-51, 2016. 
13. Aaronson NK, Ahmedzai S, Bergman B, Bullinger $M$ Cull A, Duez NJ, Filiberti A, Flechtner H, Fleishman SB, de Haes JC, et al: The European organization for research and treatment of cancer QLQ-C30: A quality-of-life instrument for use in international clinical trials in oncology. J Natl Cancer Inst 85: 365-376, 1993.

14. van Andel G, Bottomley A, Fosså SD, Efficace F, Coens C, Guerif S, Kynaston H, Gontero P, Thalmann G, Akdas A, et al: An international field study of the EORTC QLQPR 25: A questionnaire for assessing the health-related quality of life of patients with prostate cancer. Eur J Cancer 44: 2418-2424, 2008.

15. Kucway R, Vicini F, Huang R, Stromberg J, Gonzalez J and Martinez A: Prostate volume reduction with androgen deprivation therapy before interstitial brachytherapy. J Urol 167: 2443-2447, 2002.

16. Alsadius D, Olsson C, Pettersson N, Tucker SL, Wilderäng U and Steineck G: Patient-reported gastrointestinal symptoms among long-term survivors after radiation therapy for prostate cancer. Radiother Oncol 112: 237-243, 2014.

17. Gillespie C, Goode C, Hackett $\mathrm{C}$ and Andreyev HJ: The clinical needs of patients with chronic gastrointestinal symptoms after pelvic radiotherapy. Aliment Pharmacol Ther 26: 555-563, 2007.
18. Hopfgarten T, Adolfsson J, Henningsohn L, Onelöv E and Steineck G: The choice between a therapy-induced long-term symptom and shortened survival due to prostate cancer. Eur Urol 50: 280-289, 2006.

19. Andreyev HJ, Vlavianos P, Blake P, Dearnaley D, Norman AR and Tait D: Gastrointestinal symptoms after pelvic radiotherapy: Role for the gastroenterologist? Int J Radiat Oncol Biol Phys 62: 1464-1471, 2005.

20. Lilleby W, Fosså SD, Waehre HR and Olsen DR: Long-term morbidity and quality of life in patients with localized prostate cancer undergoing definitive radiotherapy or radical prostatectomy. Int J Radiat Oncol Biol Phys 43: 735-743, 1999.

21. Al-Abany M, Helgason AR, Cronqvist AK, Svensson C, Wersäll P and Steineck G: Long-term symptoms after external beam radiation therapy for prostate cancer with three or four fields. Acta Oncol 41: 532-542, 2002. 